\title{
Platelet activating factor: release from colonic mucosa in patients with ulcerative colitis and its effect on colonic secretion
}

\author{
T D Wardle, L Hall, L A Turnberg
}

\begin{abstract}
Inflammatory mediators have been implicated in the pathophysiology of ulcerative colitis. They may stimulate intestinal secretion and contribute to the production of diarrhoea. Platelet activating factor (PAF) may be responsible for a high proportion of this secretory response. Biopsy specimens from inflamed and quiescent mucosa of patients with ulcerative colitis and normal human colonic mucosa were cultured or co-cultured. The release of PAF, prostaglandin $E_{2}$, and leukotriene $\mathrm{D}_{4}$ into the culture medium was measured and the ability of this culture medium, from inflamed and normal tissues, to influence secretion in rat colonic mucosa was assessed. PAF was liberated by inflamed tissue. Its release from quiescent but not normal tissue was stimulated by medium in which inflamed mucosal biopsy tissues had been cultured and by exogenous bradykinin and 5-hydroxytryptamine, but not by histamine. PAF stimulated eicosanoid production. The rise in short circuit current produced in vitro by inflamed tissue culture medium was inhibited by the PAF receptor antagonist (CV 6209) (46\%) (32.4 (2.9) v 17.5 $\left.(1.19) \mu A . \mathrm{cm}^{-2}, p<0.005\right)$ and further by combined cyclooxygenase and lipoxygenase inhibition (indomethacin plus ICI 207968) (58\%) $\quad(32.4 \quad(2.9) \quad v \quad 13.6 \quad(1.9)$ $\left.\mu A . \mathrm{cm}^{-2}, \quad \mathbf{p}<0.005\right)$. Mepacrine and hydrocortisone attenuated considerably the electrical response evoked by medium from inflamed mucosa to a similar extent (32.4 (2.9) v $6.3(1.2)$ v $5.1(0.9) \mu A . \mathrm{cm}^{-2}$, $\mathbf{p}<0.001)$. These data suggest that PAF accounted for $46 \%$ of the culture medium secretory effect. Thus, any attempt to block its release in patients with ulcerative colitis may have only a partial effect on their symptoms.
\end{abstract}

(Gut 1996; 38: 355-361)

Keywords: arachidonic acid, phospholipase $\mathrm{A}_{2}$, cycloocygenase, lipoxygenase, eicosanoid, prostaglandin $\mathrm{E}_{2}$, leukotriene $\mathrm{D}_{4}$, platelet activating factor.

Platelet activating factor (PAF) is derived predominantly from membrane bound phosphatidylcholine. It is rapidly synthesised after activation of inflammatory cells ${ }^{1-4}$ and has been found in high concentrations in colonic mucosal biopsy tissue from patients with ulcerative colitis. ${ }^{5}$ PAF exhibits a variety of effects, in particular on inflammatory cells. These effects are mediated via specific plasma membrane receptors ${ }^{67}$ and include modulation of the immune response by stimulating the production of other mediators, vasodilation, increased vascular permeability, and the promotion of chemotaxis. ${ }^{8-12}$ PAF also stimulates mucosal chloride secretion and inhibits sodium chloride absorption, ${ }^{13}$ so it could contribute to the production of diarrhoea in ulcerative colitis. During the inflammatory response, however, many mediators are released and it is difficult to establish which is responsible for liberating PAF and which, if any, is responsible for mediating its effect on mucosal function.

We previously reported that culture medium from inflamed colitic mucosa evoked a secretory response that was partly mediated by arachidonic acid metabolites - that is prostaglandins and leukotrienes. ${ }^{14}$ Because inhibitors of these arachidonic acid metabolites failed to block all of the secretory effect, we postulated that another phospholipid derivative, PAF, might account for the remaining secretory response. To test this hypothesis we have investigated factors that influence the release of PAF from human colonic mucosa, examined its effect on colonic secretion and considered whether this effect is mediated by prostaglandins and leukotrienes.

\section{Methods}

\section{PATIENT DETAILS}

Mucosal biopsy specimens were taken from $\mathbf{4 0}$ patients during colonoscopy. All had undergone bowel preparation consisting of a three day low residue diet and, one day before the examination, a combination of $\mathrm{X}$ prep (purified senna extract; $1 \mathrm{ml} / \mathrm{kg}$ body weight) and $10 \%$ mannitol $(500 \mathrm{ml})$ modified according to the patients' symptoms.

Twenty eight patients $(16 \mathrm{M}, 12 \mathrm{~F}$, median age 38.3 years) with active proctosigmoiditis (grade 3/4) had biopsy specimens taken from inflamed rectal mucosa and also from uninflamed, 'quiescent' proximal mucosa from the ascending colon. At the time of colonoscopy nine patients were taking mesalazine $(400 \mathrm{mg}$ three times daily), six prednisolone ( 5 to $15 \mathrm{mg}$ once daily), and 10 topical steroids. Twelve patients ( $6 \mathrm{M}, 6 \mathrm{~F}$, median age 36.8 years), who were being investigated for altered bowel habit, had biopsy specimens taken from endoscopically and histologically normal colonic 
mucosa. To minimise tissue trauma all biopsies were taken with non-spiked forceps.

\section{BIOPSY CULTURE}

After removal, mucosal biopsy specimens were immediately placed in transport medium (L15, with added penicillin G 100 units/ml and streptomycin sulphate $100 \mu \mathrm{g} / \mathrm{ml}$ ); transferred to the laboratory; gently washed three times in the L15 medium; and carefully blotted, weighed, and placed in a $4 \mathrm{~cm}$ culture dish containing $1 \mathrm{ml}$ of culture medium (CMRL 1066, plus glucose $5 \mu \mathrm{g} / \mathrm{ml}$, methionine $1 \mu \mathrm{m} / \mathrm{ml}$, Tris buffer $20 \mathrm{mM}$, glutamine $3 \mathrm{mM}$, $\beta$-retinyl acetate $1 \mu \mathrm{g} / \mathrm{ml}$, penicillin $\mathrm{G} 100$ units $/ \mathrm{ml}$, streptomycin sulphate $100 \mu \mathrm{g} / \mathrm{ml}$, gentamicin $50 \mu \mathrm{g} / \mathrm{ml}$, and amphotericin $\beta 0.25 \mu \mathrm{g} / \mathrm{ml}$ ).

\section{Isolated biopsy culture}

Biopsy specimens from inflamed, quiescent, and normal mucosa were cultured to assess PAF release.

To investigate the effect of other compounds on PAF release, specimens were cultured in the presence of one of the following:

- PAF receptor antagonist (CV6209) at a final concentration of $10^{-5} \mathrm{M}$.

- Potential stimulators of PAF release bradykinin, 5-hydroxytryptamine, or histamine was added to the culture medium, producing final concentrations ranging from $10^{-10}$ to $10^{-4} \mathrm{M}$. Their respective receptor antagonists des arg leu bradykinin $\left(10^{-8} \mathrm{M}\right)$, ketanserin $\left(10^{-6}\right)$, and combined chlorpheniramine maleate and ranitidine $\left(10^{-6} \mathrm{M}\right)$ were added to a further set of cultures.

- Potential inhibitors of PAF release mepacrine and hydrocortisone (phospholipase $\mathrm{A}_{2}$ inhibitors) $10^{-5} \mathrm{M}$.

- Potential PAF effectors - prostaglandin and leukotriene release was inhibited by a combination of indomethacin and ICI $207968\left(10^{-5}\right.$ $M$ ) (cyclooxygenase and lipoxygenase inhibition, respectively).

- Combination of indomethacin, ICI 207968, and CV 6209 (combined cyclooxygenase and lipoxygenase inhibition, plus PAF receptor antagonist) all at a concentration of $10^{-5} \mathrm{M}$.

\section{Co-culture}

Mucosal biopsy specimens from either inflamed, 'quiescent', or normal tissue were co-cultured in various paired combinations in a $4 \mathrm{~cm}$ dish divided by a polypropylene barrier. This was designed, as described previously, to allow free circulation of culture medium and to prevent direct tissue contact between the two biopsy specimens. ${ }^{15}$

All culture dishes were placed in a humidified chamber maintained at $37^{\circ} \mathrm{C}$, supplied with a mixture of $95 \% \mathrm{O}_{2} / 5 \% \mathrm{CO}_{2}$, and rotated at $10 \mathrm{cycles} / \mathrm{min}$. After four hours of culture the medium was removed and divided into two aliquots. One was used for measurement of inflammatory mediator production (PAF, $\mathrm{PGE}_{2}, \mathrm{LTD}$ ) and the other for studies of mucosal transport.

\section{INFLAMMATORY MEDIATOR MEASUREMENT}

\section{PAF}

PAF was measured by commercially available radioimmunoassay kit (Amersham, Aylesbury, Bucks, UK). Performance characteristics of this assay in our laboratory were as follows: intra-assay and interassay coefficient of variation $4 \%$ and $7 \%$ respectively, recovery $91 \%$, sensitivity $0.1 \mathrm{ng} / \mathrm{ml}$. Cross reactivity $<0.6 \%$ for arachidonic acid, phosphatidylcholine and lyso PAF (Amersham, personal communication). All results were expressed as $\mathrm{fmol} / \mathrm{mg}$ wet tissue weight/h.

\section{Eicosanoids}

$\mathrm{PGE}_{2}$ and $\mathrm{LTD}_{4}$ were measured using commercially available radioimmunoassay kits (PGE 2 du Pont, UK, Stevenage, Herts, UK; $\mathrm{LTD}_{4}$, Amersham) as previously described. ${ }^{14}$ Performance characteristics of these assays in our laboratory were as follows: intra-assay and interassay coefficient of variation $\mathrm{PGE}_{2} 5 \%$, $\mathrm{LTD}_{4} 8 \%$; recovery $\mathrm{PGE}_{2} 90 \%, \mathrm{LTD}_{4} 94 \%$; sensitivity $\mathrm{PGE}_{2} 1.9 \mathrm{pg} / \mathrm{ml}, \mathrm{LTD}_{4} 4.6 \mathrm{pg} / \mathrm{ml}$. Cross reactivity: $\mathrm{PGE}_{2}$ (non-E prostaglandin) $<0.4 \%,{ }^{16} \mathrm{LTD}_{4}$ (non-sulphidopeptide leukotrienes $)<0.001 \% .17$

\section{TRANSPORT STUDIES}

\section{Rat distal colon preparation}

Unfasted male Sprague-Dawley rats were killed and the distal colon was removed immediately and bathed in oxygenated buffer. A modified in vitro technique based on that of Ussing and Zerahn was used. ${ }^{18}$ Muscle layers were stripped and the two most distal pieces of mucosa were mounted as sheets between Perspex flux chambers, with a surface area of $0.64 \mathrm{~cm}^{2}$ (VT Plastics Ltd, Warrington, UK). Spontaneous, basal transmucosal potential difference (PD) was measured on a high impedance digital voltmeter attached via fine tipped electrode bridges (3 $\mathrm{M} \mathrm{KCl}$ in 3\% agar). Short circuit current (Isc) was delivered via $1 \mathrm{M} \mathrm{NaCl}$ in $1 \%$ agar bridges, by silver/silver chloride electrodes. The electrodes were connected to a voltage clamp for automatic short circuiting. The clamp was corrected for fluid resistance between the PD and sensing bridges. Tissue conductance and resistance were calculated from the PD and Isc according to Ohm's law.

In this mucosal preparation, a rise in Isc and PD is associated with secretion of chloride ions and we have used this rise in electrical parameters as a proxy for anion secretion.

Both surfaces of each mucosal sheet were bathed with $5 \mathrm{ml}$ of isotonic buffer containing: $\mathrm{Na} 146 \mathrm{mM}, \mathrm{K} 4.2 \mathrm{mM}, \mathrm{Cl} 125.8 \mathrm{mM}, \mathrm{HCO}_{3}$ $26.6 \mathrm{mM}, \mathrm{H}_{2} \mathrm{PO}_{4} 0.2 \mathrm{mM}, \mathrm{HPO}_{4} 1.2 \mathrm{mM}$, Ca $1.2 \mathrm{mM}, \mathrm{Mg} 1.2 \mathrm{mM}$, and glucose $10 \mathrm{mM}$, at $\mathrm{pH} 7 \cdot 4$. The bathing media were maintained at a constant temperature of $37^{\circ} \mathrm{C}$ and stirred and oxygenated via a bubble lift system using $95 \%$ $\mathrm{O}_{2} / 5 \% \mathrm{CO}_{2}$.

The following compounds were added to the fluid bathing either the basolateral or the 
apical aspect of the rat colonic mucosal preparation after electrical stability had been reached (usually 60 minutes).

- PAF: this was added to the fluid bathing stripped rat distal colon to produce a range of concentrations from $10^{-10}$ to $10^{-4} \mathrm{M}$. Changes in PD, Isc, and resistance were recorded.

- PAF receptor antagonist CV6209: this was added to the bathing fluid at a final concentration of $10^{-6} \mathrm{M}$, immediately before PAF at concentrations which had evoked a maximal and half maximal electrical response.

- Combined indomethacin and ICI 207968: this combination $\left(10^{-5} \mathrm{M}\right)$ was added to block production of prostaglandin and leukotrienes immediately before the addition of PAF (at concentrations which had evoked a maximal and half maximal electrical response).

- Culture medium: culture medium $(100 \mu \mathrm{l})$ was added to the basolateral aspect of rat distal colonic mucosa and electrical parameters, as described above, were measured. This process was repeated using medium from biopsy specimens cultured in the presence of factors influencing the release of PAF as detailed above.

\section{CHEMICALS}

The 5 lipoxygenase inhibitor (ICI 207968) was kindly supplied by $\mathrm{Dr} R$ Dowell, Imperial Chemical Company, Alderley Edge, UK. The platelet activating factor receptor antagonist CV 6209 was kindly donated by Dr Tsukamoto (Takeda Chemical Industries, Ozako 532, Japan). PAF, indomethacin, mepacrine, bradykinin, des arg leu bradykinin, histamine, chlorpheniramine maleate, and 5hydroxytryptamine were obtained from Sigma Chemical Company, Poole, Dorset, UK. Ketanserin was purchased from Janssen Biotech, Olen, Belgium.

\section{STATISTICAL ANALYSIS}

All values are expressed as the mean (SEM). Statistical comparisons were performed using paired or unpaired $t$ tests. ${ }^{19}$ Two tailed $\mathrm{p}$ values were used throughout.

\section{Results}

PAF PRODUCTION

Inflamed tissue cultured in isolation produced 795 (45) fmol of PAF/mg wet tissue weight/h. PAF was not detectable in the medium from either quiescent colitic or normal mucosa $(<26 \mathrm{fmol} \mathrm{PAF} / \mathrm{mg}$ wet tissue weight $/ \mathrm{h})$.

Factors influencing $P A F$ production

- PAF $\left(10^{-9} \mathrm{M}\right)$ added to inflamed mucosa liberated significantly less PAF than expected (I+exogenous PAF: actual: 1314 (106) $v$ expected: $1795, \mathrm{p}<0 \cdot 01$ ).

- PAF receptor antagonist (CV6209): basal production of PAF was not influenced by its receptor antagonist (basal: 795 (45) $v 792$ (49), NS) (Fig 1).

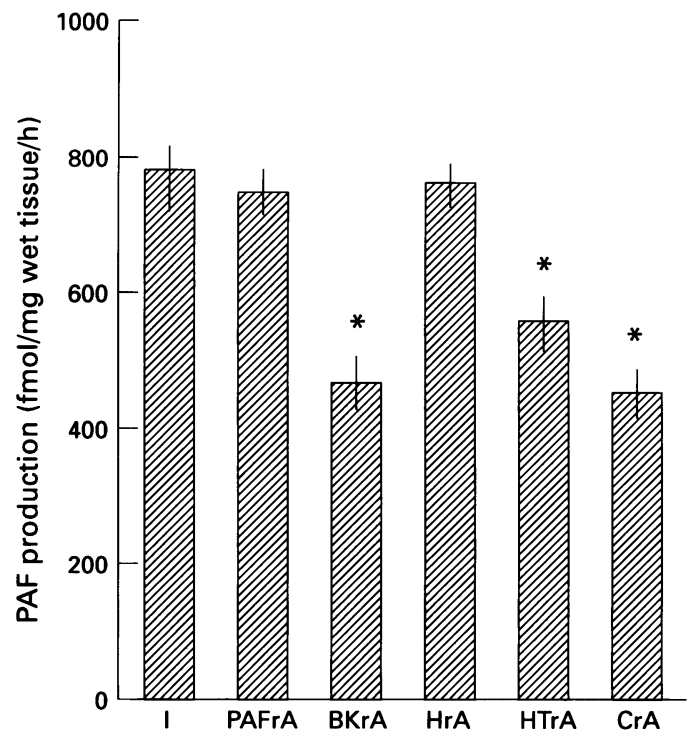

Figure 1: The effect of receptor antagonists on platelet activating factor (PAF) production by cultured inflamed colonic mucosa (mean (SEM)). I=inflamed

$P A F r A=P A F$ receptor antagonist; $B K r A=$ bradykinin receptor antagonist; $\mathrm{Hr} A=$ histamine receptor antagonist; $H \operatorname{Tr} A=5 H T$ receptor antagonist; $\mathrm{Cr} A=$ combined $B \mathrm{Kr} A+\mathrm{HrA}+5 \mathrm{HTr} A ;$ * Significantly different from basal value $(p<0.01)$.

- (1) Bradykinin: in inflamed tissue, bradykinin stimulated a concentration dependent increase in PAF generation. The maximum stimulation was evoked at a bradykinin concentration of $10^{-8} \mathrm{M}$ (basal: 795 (45) $v$ bradykinin stimulated: $972(71), \mathrm{p}<0.01)$ (Fig 2).

Bradykinin stimulated PAF production by quiescent (basal: $\mathrm{O} v$ bradykinin stimulated: 183 (21)) but not normal tissue.

(2) Bradykinin receptor antagonist: basal PAF production by inflamed tissue was attenuated by the bradykinin receptor antagonist des arg leu bradykinin (basal: 794 (45) v 494 (28), $\mathrm{p}<0.005$ ) (Fig 1).

- (1) Histamine: Histamine, ranging from $10^{-10}$ to $10^{-4} \mathrm{M}$, did not significantly influence PAF production by inflamed mucosa (Fig 2). Histamine did not stimulate PAF production by either quiescent colitic or normal tissue.

(2) Histamine receptor antagonists: basal PAF production by inflamed tissue was not significantly influenced by histamine receptor antagonists (795 (45) $v 763$ (49), respectively, NS) (Fig 1).

- (1) 5-Hydroxytryptamine: this stimulated PAF production by inflamed mucosa (maximal response at $10^{-6} \mathrm{M} 923(58) v$ basal 795 (45), $\mathrm{p}<0.01)$ and by quiescent colitic (169 (18) $v$ basal 0), but not normal, tissue (Fig 2).

(2) 5-Hydroxytryptamine receptor antagonist, ketanserin attenuated PAF release by inflamed mucosa (563) (21) v 795 (45): $\mathrm{p}<0.005$ ) (Fig 1).

- Combined treatment with bradykinin, histamine, and 5-hydroxytryptamine evoked a 59\% increase in PAF release by inflamed tissue when compared with basal release (1260 (93) $v 795$ (45), $\mathrm{p}<0.005$ ) (Fig 1).

- Cyclooxygenase and lipoxygenase inhibitors: the basal production of PAF by inflamed 


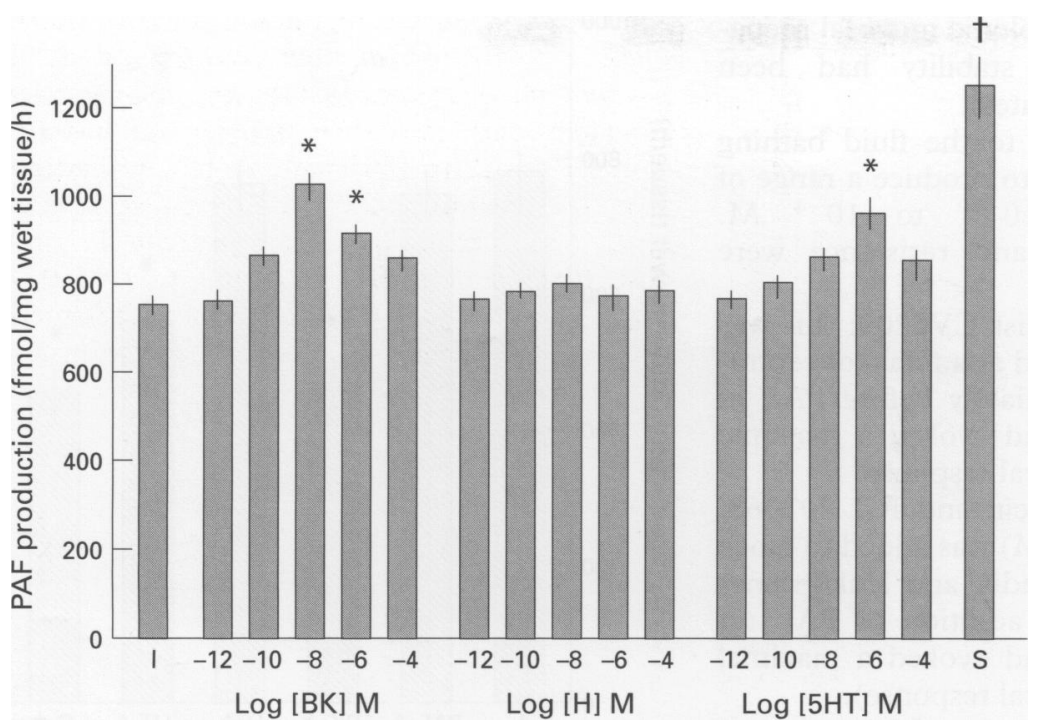

Figure 2: The effect of agonists on platelet activating factor (PAF) production by cultured colonic mucosa (mean (SEM)), $I=$ inflamed; $B K=$ bradykinin; $H=$ histamine:

$5 H T=5$-hydroxytryptamine. $S=$ combined effect of three agonists. ${ }^{*}$ Significantly different from basal value $(p<0.01)$; †significantly different from basal value $(p<0.001)$.

tissue was not significantly influenced by combined cyclooxygenase and lipoxygenase inhibition (795 (45) v 759 (53), NS) (Fig 3).

- Phospholipase $\mathrm{A}_{2}$ inhibition with either mepacrine or hydrocortisone significantly reduced PAF release when compared with untreated inflamed mucosa (104 (11): 119 (12) $v 795$ (45) respectively, p<0.001) (Fig 3). - Co-culture: in comparison with one piece of inflamed mucosa, PAF release was not stimulated by co-culture of two pieces of inflamed tissue (I alone $=795$ (45) $b \mathrm{I}+\mathrm{I}=828$ (74), NS) (Table I). PAF was not produced by either cocultured quiescent or normal mucosa. Coculture of one piece of inflamed mucosa with one piece of quiescent mucosa produced 558 (40) fmol of PAF/wet tissue weight/h (Table I). This was significantly greater than the expected quantity of PAF calculated from the mean production of $P A F$ from $I+I$ and $Q+Q$ divided by the tissue weight (I+Q calculated $=366, \quad p<0.01)$. The expected quantity of PAF produced by an inflamed and control combination was calculated in the same way $(I+C$ calculated $=358)$, this was similar to the actual value (I+C calculated $=358 v \mathrm{I}+\mathrm{C}=341$ (35), NS).

Platelet activating factor (PAF) production (fmol/mg wet tissue weight/h) by $a$ series of co-cultures

\begin{tabular}{ll}
\hline Co-culture & $\begin{array}{c}P A F \text { production } \\
(\text { fmollmg/h) }\end{array}$ \\
\hline $\mathrm{C}+\mathrm{C}$ & - \\
$\mathrm{Q}+\mathrm{Q}$ & - \\
$\mathrm{I}+\mathrm{I}$ & $828(74)$ \\
$\mathrm{I}+\mathrm{C}$ & $341(35)$ \\
$\mathrm{I}+\mathrm{C}$ (calc) & 358 \\
$\mathrm{I}+\mathrm{Q}$ & $558(40)^{\star}$ \\
$\mathrm{I}+\mathrm{Q}$ (calc) & 366 \\
\hline $\mathrm{C}=$ control; $\mathrm{Q}=$ quiescent; \\
$\mathrm{I}=$ inflamed; calc=calculated; \\
$\star=$ significantly different from \\
calculated value $(\mathrm{p}<0 \cdot 01)$. \\
$\mathrm{n}=10$ co-cultures/each \\
combination.
\end{tabular}

Reactions between PAF and eicosanoids

Inflamed tissue produced significantly more $\mathrm{PGE}_{2}$ and $\mathrm{LTD}_{4}$ than either quiescent or normal tissue (Figs 4 and 5). Exogenous PAF stimulated a concentration dependent increase in the production rates of $\mathrm{PGE}_{2}$ and $\mathrm{LTD}_{4}$ by inflamed, quiescent, and normal tissues, with a maximum response at $10^{-5} \mathrm{M}$ (Figs 4 and 5).

\section{TRANSPORT STUDIES}

PAF concentration response curve

When added to the fluid bathing the basolateral aspect of rat colonic mucosa, PAF produced a rapid increase in Isc which exhibited a biphasic response peaking after 5 and 16

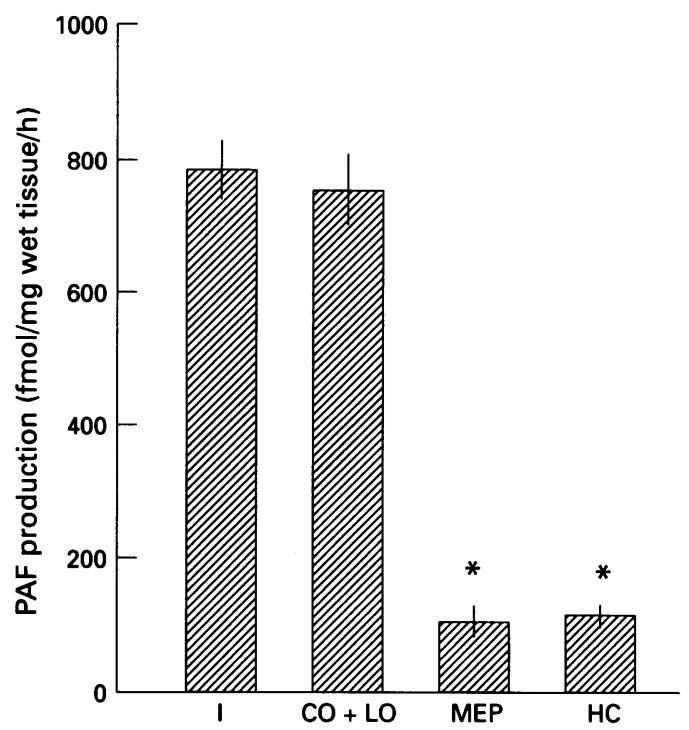

Figure 3: The influence of inhibitors on platelet activating factor (PAF) production by cultured inflamed colonic mucosa (mean (SEM)). I= inflamed; $C O=$ cyclooxygenase inhibitor; $L O=$ lipoxygenase inhibitor; $M E P=$ mepacrine; $H C=$ hydrocortisone. ${ }^{\star}$ Significantly different from basal value $(p<0 \cdot 001)$.

minutes (Fig 6). The concentration response curve for PAF gave an EC50 of $3 \times 10^{-7} \mathrm{M}$. PAF generated a parallel increase in PD and a modest rise in tissue conductance.

When added to the apical aspect, PAF did not evoke any electrical response. Thus, in subsequent experiments PAF was only added to the basolateral aspect of rat colonic mucosa.

\section{Factors influencing the PAF evoked electrical response}

- While pretreatment with the PAF receptor antagonist CV6209 did not significantly influence the basal Isc, it did prevent the PAF evoked increase in Isc (basal 48.9 (4.3) CV $6209+$ PAF $\left.51 \cdot 4(6 \cdot 2) \mu \mathrm{Acm}^{-2}\right)$.

- Pretreatment of the basolateral surface of rat colonic mucosa with both cyclooxygenase and lipoxygenase inhibitors virtually abolished the electrical response, when compared with the basal Isc (8.3 (1.6) $v 48.9(4.3) \mu \mathrm{Acm}^{-2}$, $\mathrm{p}<0.001)$.

Basolateral addition of cyclooxygenase and lipoxygenase inhibitors significantly attenuated the short circuit response to platelet activating factor at maximal and half maximal concentrations (71.4 (6.9) $v 18.1(2.2) ; 35.7(3.5)$ respectively, $\mathrm{p}<0.005$, Fig 6$)$.

\section{Effect of culture medium on electrical response}

Medium from inflamed tissue, applied to the basolateral. half chamber, generated a significantly greater Isc than medium from either quiescent or control tissue $(32.4(2.7) v 7.8$ $\left.(1 \cdot 1): 7 \cdot 1(0 \cdot 9), \mu \mathrm{Acm}^{-2}, \mathrm{p}<0 \cdot 001\right)$. Freshly prepared culture medium did not evoke any change in baseline electrical activity (Fig 7).

Effect of culture medium from tissue treated with combined cyclooxygenase and lipoxygenase inhibitors. There was no significant difference between the Isc responses evoked by culture media from normal tissue that were either 


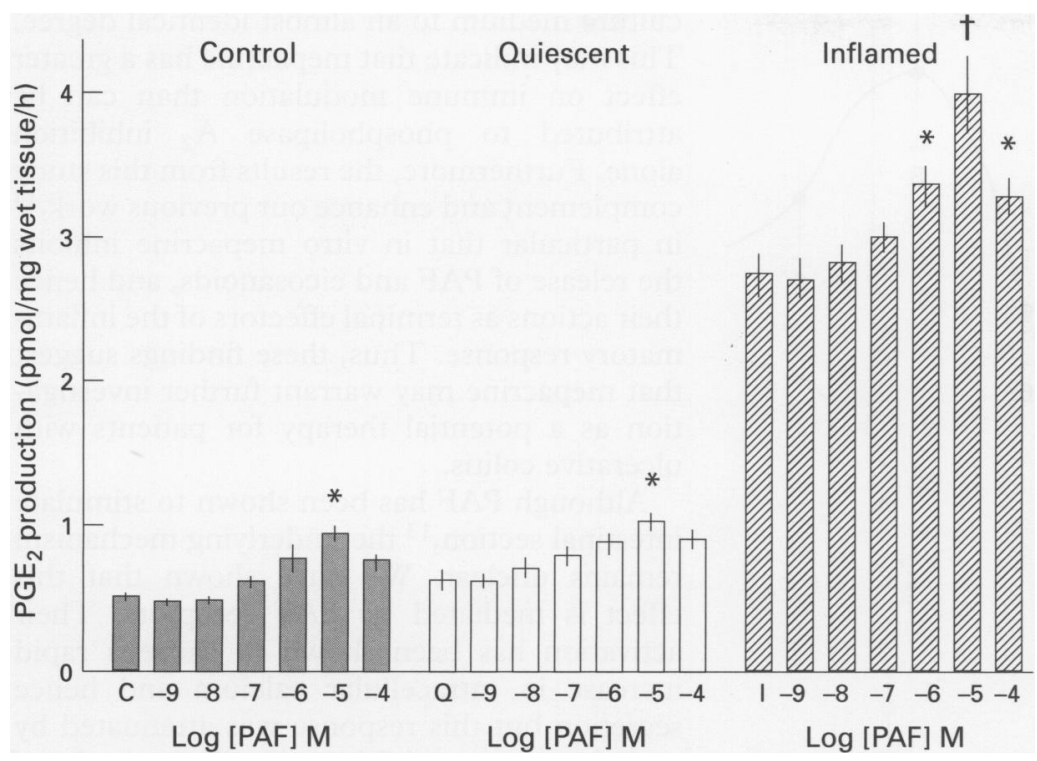

Figure 4: The concentration dependent effect of platelet activating factor (PAF) on prostaglandin $E_{2}\left(P G E_{2}\right.$ ) production (pmol/mg wet tissue/h) by cultured colonic mucosa (mean (SEM)). * Significantly different from respective basal value $(p<0 \cdot 01)$; tsignificantly different from respective basal value $(p<0.005)$.

untreated or exposed to combined cyclooxygenase and lipoxygenase inhibition $(7 \cdot 1(0.9) v$ $6 \cdot 7$ (1), $\mu \mathrm{Acm}^{-2}, \mathrm{NS}$ ) (Fig 7). Similar results were obtained with media from quiescent tissue, either untreated or exposed to combined cyclooxygenase and lipoxygenase inhibition (Fig 7). Culture medium from inflamed tissue treated in the same way, however, produced a significantly lower Isc when compared with medium from untreated inflamed mucosa (13.6 (1.9) v 32.4 (2.7), $\left.\mu \mathrm{Acm}^{-2}, \mathrm{p}<0.005\right)$. Effect of culture medium from tissue treated with $P A F$ receptor antagonist. CV 6209 did not influence the modest rise in electrical activity seen with medium from either normal or quiescent biopsies (Fig 7). However, medium from inflamed tissue cultured in the presence of $\mathrm{CV}$ 6209 produced a significantly lower Isc than medium from untreated inflamed mucosa

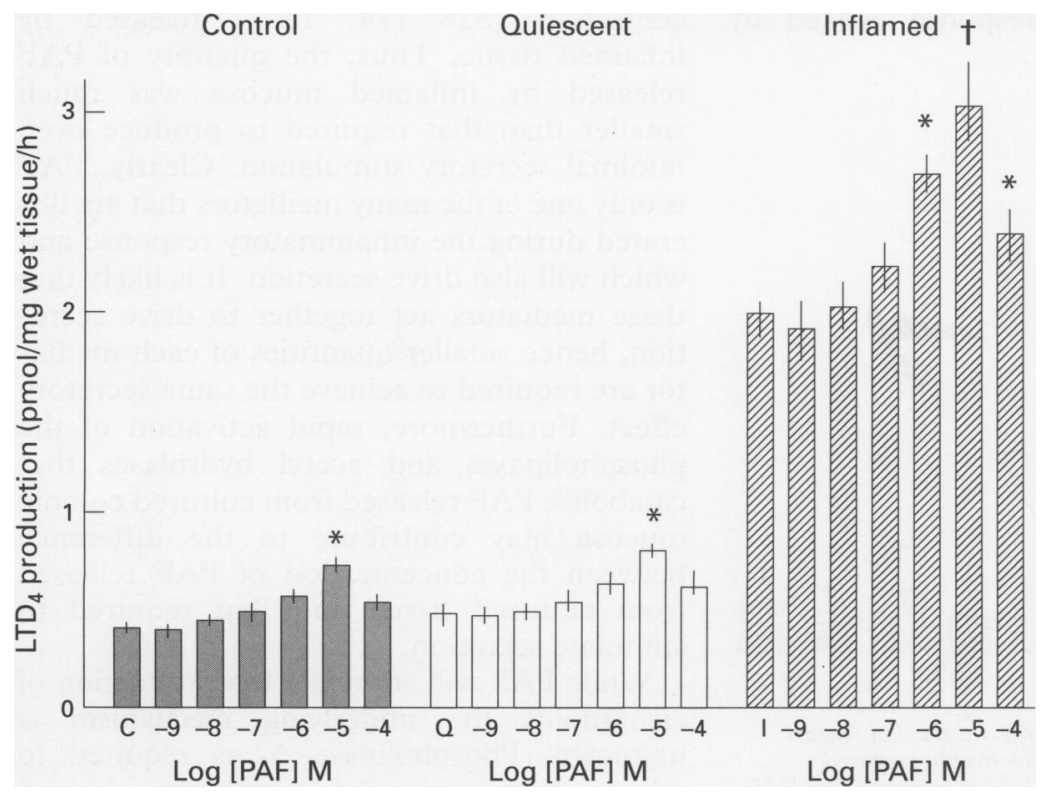

Figure 5: The concentration dependent effect of platelet activating factor on leukotriene $\mathrm{D}_{4}$ (LTD 4 ) production (pmolmg wet tissue/h) by cultured colonic mucosa (mean (SEM)).

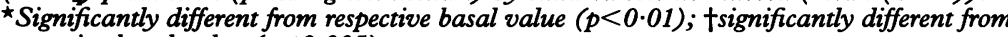
respective basal value $(p<0.005)$.
(17.5 (1.9) v 32.4 (2.9), $\left.\mu \mathrm{Acm}^{-2}, \mathrm{p}<0.005\right)$. Effect of culture medium from tissue treated with a combination of cyclooxygenase and lipoxygenase inhibitors plus the PAF receptor antagonist. Normal tissue treated with this combination produced medium which evoked an Isc significantly less than medium from untreated tissue (3.6 (0.3) v 7.1 (0.9); $\left.\mu \mathrm{Acm}^{-2}, \mathrm{p}<0.01\right)$ (Fig 7). Culture medium from inflamed mucosa, after this combined treatment, produced a significantly lower Isc response than medium from untreated mucosa $(9.9(0.9) v$ $\left.32.4(2.9) \mu \mathrm{Acm}^{-2}, \mathrm{p}<0.005\right)$.

Effect of culture medium from tissue treated with phospholipase $A_{2}$ inhibitors. Culture medium from normal mucosa treated with either mepacrine or hydrocortisone produced an Isc which was significantly lower than medium from either untreated tissue or from tissue exposed to combined cyclooxygenase and lipoxygenase inhibition $(3 \cdot 4(0 \cdot 4): 3 \cdot 2(0 \cdot 3) v$ $7 \cdot 1$ (0.9): $6 \cdot 7$ (1), $\mu \mathrm{Acm}^{-2}$, respectively, $\mathrm{p}<0.01$ ) (Fig 7). Similar results were obtained with culture medium from quiescent tissue. Medium from inflamed tissue treated with either mepacrine or hydrocortisone significantly attenuated the short circuit response when compared with medium from either untreated mucosa or mucosa cultured in the presence of combined cyclooxygenase and lipoxygenase inhibition $(6 \cdot 3(1 \cdot 2): 5 \cdot 1(0.9) v$ $32 \cdot 4(2 \cdot 7): 13.6(1.9), \mu \mathrm{Acm}^{-2}$ respectively, $\mathrm{p}<0.01)$.

\section{Discussion}

In these studies we have shown that inflamed mucosa but not quiescent mucosa from patients with ulcerative colitis releases PAF into culture medium. Furthermore, quiescent mucosa releases PAF when stimulated with bradykinin, 5-hydroxytryptamine, and cocultured inflamed mucosa. Mucosa from normal, 'control' patients, however, did not produce any detectable PAF. Culture medium from any of the tissues will evoke an electrical response in stripped rat colon.

Inflamed tissue liberated PAF in greater quantities than previously reported, ${ }^{5}$ and this liberation was enhanced by exogenous bradykinin and 5-hydroxytryptamine. Therefore, it was not surprising to find that PAF release was attenuated by treatment with either des arg leu bradykinin or ketanserin. The combined effect of these two antagonists was only sufficient to reduce PAF production by $50 \%$. Presumably, other factors including those liberated by the enteric nervous and neuroendocrine systems are involved in PAF release. Although PAF was not detectable in quiescent mucosal cultures, its release was stimulated by exogenous bradykinin, 5-hydroxytryptamine, and co-culture with colitic mucosa. These stimulants, however, did not influence control mucosa, unlike calcium ionophore and antihuman IgE, which have been shown to induce the release of PAF from normal control tissue as well as increase the production by inflamed tissue. ${ }^{5}$ Therefore, both control and quiescent tissue may be stimulated to liberate PAF but it 


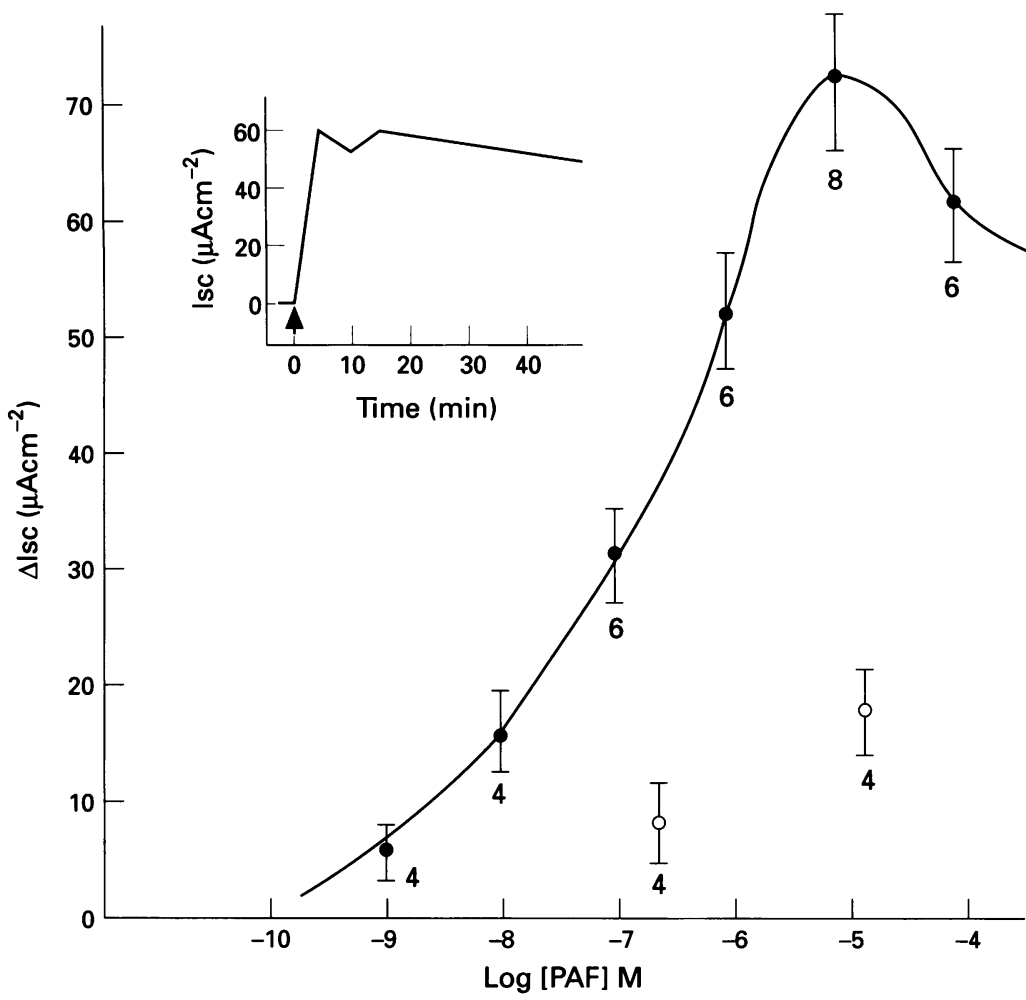

Figure 6: Platelet activating factor (PAF) concentration response curve in stripped rat distal colon (closed circles). Open circles = pretreatment with combined cyclooxygenase and lipoxygenase inhibitors. Isc = short circuit current (mean (SEM)). Number of rat mucosal preparations under each point. Inset shows the Isc response following basolateral addition of $P A F$.

seems that under normal circumstances this membrane derived mediator is not produced in detectable amounts.

The PAF receptor antagonist did not influence PAF release by cultured mucosa. However, the phospholipase $\mathrm{A}_{2}$ inhibitors, mepacrine and hydrocortisone, significantly reduced the production of PAF and other phospholipid derivatives. ${ }^{14}$ Considering the wide range of immunomodulatory activities of steroids and the fact that mepacrine is only a phospholipase $\mathrm{A}_{2}$ inhibitor, it was surprising to find that mepacrine and hydrocortisone reduced the electrical response evoked by

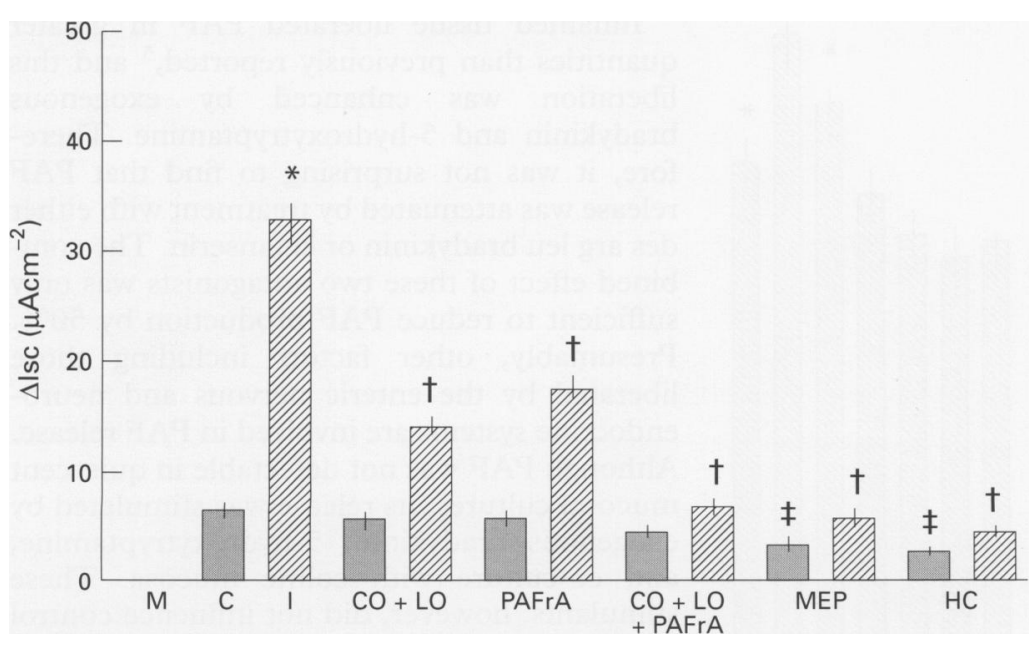

Figure 7: The effect of culture medium on the Isc across stripped rat distal colon (mean (SEM)), $n=6$ preparations/column. I=inflamed; $C=$ control; $M=$ freshly prepared medium; $C O+L O=$ combined cyclooxygenase and lipoxygenase inhibition; $P A F r A=P A F$ receptor antagonist; $C O+L O+P A F r A=$ combination of cyclooxygenase and lipoxygenase inhibitors plus $P A F$ receptor antagonist; $M E P=$ mepacrine; $H C=$ hydrocortisone.

* Significantly greater than control tissue $(p<0 \cdot 001)$; †significantly less than respective untreated tissue $(p<0.005)$; $\ddagger$ significantly less than respective untreated tissue $(p<0.01)$. culture medium to an almost identical degree. This may indicate that mepacrine has a greater effect on immune modulation than can be attributed to phospholipase $\mathrm{A}_{2}$ inhibition alone. Furthermore, the results from this study complement and enhance our previous work, ${ }^{14}$ in particular that in vitro mepacrine inhibits the release of PAF and eicosanoids, and hence their actions as terminal effectors of the inflammatory response. Thus, these findings suggest that mepacrine may warrant further investigation as a potential therapy for patients with ulcerative colitis.

Although PAF has been shown to stimulate intestinal section, ${ }^{13}$ the underlying mechanism remains unclear. We have shown that this effect is mediated by PAF receptors. Their activation has been shown to cause a rapid increase in intracellular calcium and hence secretion but this response was attenuated by cyclooxygenase inhibition. ${ }^{13}$ While both of these mechanisms may be important, their relevant contributions to PAF induced secretion were unknown. In this study combined inhibition of cyclooxygenase and lipoxygenase activity in rat colonic mucosa attenuated the PAF evoked secretory response by $70 \%$. Furthermore, the maximum Isc response evoked by PAF occurred at the same concentration at which maximum eicosanoid release was stimulated $\left(10^{-5} \mathrm{M}\right) \cdot{ }^{14}$ Thus, these data suggest that eicosanoids, via their action on cAMP, are responsible for most of the PAF mediated secretory effect, while the remainder is likely to be related to changes in intracellular calcium.

In cultured colonic tissue, PAF stimulated a concentration dependent rise in both $\mathrm{PGE}_{2}$ and $\mathrm{LTD}_{4}$ : similarly, PAF has been shown to augment the production of $\mathrm{LTB}_{4}$ and 5 HETE. ${ }^{20-22}$ The threshold for a response in colonic tissue was in the range of $10^{-8} \mathrm{M}-10^{-9} \mathrm{M}$, with a maximum stimulatory effect at a PAF concentration of $10^{-5} \mathrm{M}$, considerably higher than the measured concentration (828 (74) fmol) released by inflamed tissue. Thus, the quantity of PAF released by inflamed mucosa was much smaller than that required to produce even minimal secretory stimulation. Clearly, PAF is only one of the many mediators that are liberated during the inflammatory response and which will also drive secretion. It is likely that these mediators act together to drive secretion, hence smaller quantities of each mediator are required to achieve the same secretory effect. Furthermore, rapid activation of the phospholipases and acetyl hydrolases that catabolise PAF released from cultured colonic mucosa may contribute to the difference between the concentration of PAF released from cultured tissue and that required to stimulate secretion.

While PAF will stimulate the production of eicosanoids the underlying mechanism is unknown. Phospholipase $A_{2}$ is required to release both types of membrane derived mediator, but it is unlikely to be implicated in this role as we have demonstrated that PAF attenuates rather than stimulates its own 
release. Although PAF may upregulate the activity of both cyclooxygenase and lipoxygenase, it seems likely that the PAF stimulated increase in both intracellular calcium ${ }^{12}$ and eicosanoid output is mediated by phospholipase C.

Although PAF stimulated eicosanoid release, these compounds did not account for all of its secretory action. Inhibition of phospholipase $\mathrm{A}_{2}$ derived secretagogues with either mepacrine or hydrocortisone reduced the culture medium evoked electrical response by approximately $81 \%$, of which eicosanoids contributed nearly $60 \%$ and presumably PAF the remainder. There is, however, some disparity between this presumed secretory influence attributed to PAF (21\%), and the actual response that it evoked (46\%). Furthermore, medium from inflamed tissue treated with combined inhibition of cyclooxygenase, lipoxygenase, and PAF receptors attenuated the Isc response by $69 \%$, of which eicosanoids accounted for $58 \%$. This disparity between the presumed and actual secretory response evoked by PAF indicates that much of this PAF response is mediated by eicosanoids. Although platelet activating factor and eicosanoids account for $69 \%$ of the secretory response evoked by culture medium, a further $12 \%$ is attributed to compounds that are antagonised by both mepacrine and hydrocortisone and it is likely that phospholipase $\mathrm{C}$ derivatives are involved. The residual medium evoked electrical response is presumably a reflection of a variety of cytokines and compounds released by the enteric nervous system.

It is interesting to speculate that as PAF accounted for, at most, $46 \%$ of the culture medium secretory effect, any therapeutic attempts to block PAF release/receptors in patients with ulcerative colitis will have a limited effect on their symptoms. Inhibition of one individual phospholipid derivative, or even one group of phospholipid derivatives is highly unlikely to produce any therapeutic benefit - as exemplified by the failure of non-steroidal antiinflammatory drugs in the treatment of ulcerative colitis. ${ }^{14} 23-25$

In conclusion, we have shown not only that PAF stimulates colonic secretion, accounting for $46 \%$ of the secretory response evoked by culture medium from colitic tissue, but also that its actions are mediated, predominantly by eicosanoids.

We thank the Ileostomy Association for their financial support and continued interest in our work. We are indebted both to Dr $\mathrm{R}$ Dowell (Imperial Chemical Industry) for donating the lipoxygenase inhibitor ICI 207968, and Takeda Chemical Industries for providing the platelet activating factor receptor antagonist CV 6209. We also thank Carol McDonna for typing the manuscript.
1 Benveniste J, Henson PM, Cochrane CG. Leukocyte dependent histamine release from rabbit platelets. The Role for IgE, basophils and a platelet activating factor. f Exp Med 1972; 136: 1356-77.

2 Albert DH, Snyder F. Biosynthesis of 1-alkyl-1-acetyl-snglycero-3-phosphocholine (PAF) from 1-alkyl-2-acyl-snglycero-3-phosphocoline by rat alveolar macrophages. F Biol Chem 1983; 25: 97-102.

Sanchez-Crespo M, Alonson F, Edigo J. PAF in anaphylaxes and phagocytosis. Immunology 1980; 40: 645-55.

4 Chignard M, Le Couedic JP, Tence M, Benveniste J. The role of PAF in platelet aggregation. Nature 1979; 279: 799-800.

5 Eliakim R, Karmeli F, Razin E, Rachmilewitz D. Role of platelet activating factor in ulcerative colitis. Enhanced production during active disease and inhibition by sulfasalazine and prednisolone. Gastroenterology 1979; 95: 1167-72.

6 Hwant SB, Lam MH. Ionic and GTP regulation of binding of PAF to receptors and PAF induced activation of GTPase in rabbit platelet membranes. F Biol Chem 1986;
261: 532-7.

7 Valone FG, Goetzl EJ. Specific binding by human polymorphonuclear leucocytes of the immunological mediator. Immunology 1982; 48: 141-8.

8 Doebber JW, Wu MS, Shen TY. Platelet activating factor (PAF) intravenous infusion in rat stimulates vascular lysosomal hydrolase secretion independent of blood neutrophils. Biochem Biophys Res Commun 1984; 125: 980-7.

9 Humphrey DM, McManus LM, Satouchi K, Hanahan DJ, Pinckard RB. Vasoactive properties of acetyl glyceryl ether phosphorycholine and analogues. Lab Invest 1982; 46: 422-7.

10 McManus LM, Hanahan DJ, Demopoulos CA, Pinckard RN. Pathobiology of the intravenous infusion of acetyl glyceryl ether phosphorycholine (AGEPG), a synthetic
platelet activating factor (PAF) in the rabbit. F Immunol platelet activating factor

11 Poitenin B, Mencia-Heurta JM, Roubin R, Benveniste J. Role of PAF acether in neutrophil activation. In: Said SL. The pulmonary circulation and acute lung injury. Moun Kisco, NY: Future Publishing, 1985: 357-73.

12 Lapetina EG. Platelet activating factor stimulates the phosphatidyl inositol cycle. $\mathcal{F}$ Biol Chem 1982; 257: 7314-7.

13 Bern MJ, Sturbaum CN, Karayalcin SS, Berschneider HM Wachsman JT, Powell DW. Immune system control of rat and rabbit colonic electrolyte transport. $\mathcal{f}$ Clin Invest 1989; 83: 1810-20.

14 Wardle TD, Hall L, Turnberg LA. Interrelationships between inflammatory mediators released from colonic between inflammatory mediators released from colonic mucosa in ulcerative colitis, and

15 Wardle TD, Hall L, Turnberg LA. Use of co-culture of colonic mucosal biopsies to investigate the release of eicosanoids by inflamed and uninflamed mucosa from patients with inflammatory bowel disease. Gut 1992; 33: 1644-51.

$16 \mathrm{Du}$ Pont. Measurement of prostaglandin $E_{2}$ in plasma and tissue samples. Stevenage, Herts: New Research (Du Pont de Nemours), 1988.

17 Amersham Int. Leukotriene $\mathrm{C}_{4} / \mathrm{D}_{4} / \mathrm{E}_{4}$ assay system Aylesbury, Bucks: Amersham International PLC, 1988.

18 Ussing $\mathrm{HH}$, Zerahn $\mathrm{K}$. Active transport of sodium as a source of electric current in the short circuited isolated source of electric current in the short circuited
frog skin. Acta Physiol Scand 1951; 23: 110-27.

19 Snedecor GW, Cochran WG. Statistical methods. 7th ed. Amedecor GW, Cochran WG. Statistical Iowa: Iowa State University, 1980.
Ames,

$20 \mathrm{Lin}$ AH, Morton DR, Gorman RR. Acetyl-glyceryl-ether phosphorylcholine stimulates $\mathrm{LTB}_{4}$ synthesis in human polymorphonuclear leukocytes. $\mathcal{f}$ Clin Invest 1982; 70 1058-62.

21 Hopkins NK, Schaub RG, Gorman RR. Acetyl-glycerylether phosphorylcholine (PAF acether) and leukotriene $\mathrm{B}_{4}$ mediated neutrophil chemotaxis through an intact endothelial cell monolayer. Biochim Biophys Acta 1984; 805: 30-6.

22 O'Flaherty JT, Thomas MJ, Hammett MJ, Carroll C, McCall CE, Wykle RL. 5 L-hydroxy-6,8,11,14 eicosatetranoate potentiates the human neutrophil degranulating tranoate potentiates the human neutrophil degranulating Commun 1983; 111: 1-7.

23 Hawkey CJ, Rampton DS. Prostaglandins in the gastrointestinal mucosa, are they important in its function, disease or treatment? Gastroenterology 1985; 89: 1162-8.

24 Rampton DS, Sladen GE. Relapse of ulcerative proctitis during treatment with non-steroidal anti-inflammatory drugs. Postgrad Med $₹$ 1981; 57: 297-9.

25 Rampton DS, Sladen GE. Prostaglandin inhibitors in ulcerative colitis: flurbiprofen compared with conventional treatment. Prostaglandins 1987; 21 : 417-25. 